\title{
POLÍTICAS EDUCACIONAIS, DIREITOS HUMANOS E FORMAÇÃO DO PROFESSOR
}

\author{
Kátia Siqueira de Freitas (UCSAL)* \\ Ailana Freitas Rocha (UCSAL)**
}

\section{RESUMO}

0 artigo visa, na sua centralidade, a apresentar resultados da pesquisa realizada sobre a relação entre políticas educacionais, direitos humanos e formação do professor. 0 texto se refere à Resolução CNE/CP no 1/2012 do Conselho Pleno do Conselho Nacional de Educação - CPCNE - órgão ligado ao Ministério da Educação, que estabelece a inserção da legislação em direitos humanos nos currículos dos cursos de formação do professor, focando nos cursos de Pedagogia. Foi realizado um levantamento bibliográfico, abarcando documentos e leis, na perspectiva de mapear como as políticas educacionais são contempladas no processo de formação desse profissional. Do ponto de vista teórico, foram tomados como referência os seguintes autores: Novaes (2014) e Vieira (2007), com relação às políticas educacionais, Candau (1999) e Comparato (2008), no estudo dos direitos humanos. Além da Resolução 1 de 2012 do CPCNE, foram destacadas leis e normas internacionais e nacionais que regulamentam as políticas de educação em direitos humanos. A investigação de caráter qualitativo, exploratório e descritivo, realizada entre 2016 e 2019, teve como campo empírico três universidades. Foram entrevistados coordenadores do curso de Pedagogia, professores e alunos, que também responderam a um questionário. Resultados da pesquisa indicam que conteúdos e questões sobre os direitos humanos ainda requerem maior visibilidade, inserção nos currículos formais dos cursos de licenciatura - especialmente nos de Pedagogia - na prática de sala de aula, assim como nas atividades da pesquisa e da extensão. Indicam também que nem sempre a transversalidade requerida é atendida nos projetos político-pedagógicos.

Palavras-chave: Política Educacional; Direitos Humanos; Educação em Direitos Humanos.

\section{ABSTRACT \\ EDUCATIONAL POLICIES, HUMAN RIGHTS AND TEACHER TRAINING}

The main objective of this article is to present the results of research on the

* Professora da Universidade Católica de Salvador. E-mail: sfkatia@gmail.com

** Doutora pelo Programa de Pós-graduação em Políticas Sociais e Cidadania, da Universidade Católica de Salvador. E-mail: Afrlawyer@hotmail.com 
relationship between educational policies, human rights and teacher training. The text refers to Resolution 1 of 2012 of the Plenary Council of the National Council of Education - a body linked to the Ministry of Education, which establishes the insertion of human rights legislation in the curricula of teacher training courses, focusing on pedagogical courses. A bibliographic and legal survey was carried out in order to map out how the educational policies transpire in the process of developing professional training. From the theoretical point of view, the following authors were taken as references: Novaes (2014) and Vieira (2007) in relation to educational policies, Candau (1999) and Comparato (2008) in the study of human rights. In addition to Resolution 1 of 2012 of the National Council of Education, international and national laws and norms that regulate education policies to promote human rights were highlighted. The qualitative, exploratory and descriptive research took place at three universities carried out between 2016 and 2019 . Coordinator, teachers and students of the pedagogy course were interviewed and answered a questionnaire. The results of our research indicate that the topic of human rights still requires greater attention and inclusion in the formal curricula of undergraduate courses, especially in education classes, teaching practicums, as well as research and extension activities. They also indicate that the proposed intersection is not always met in the Pedagogical Political Projects.

Keywords: Educational politics; Human rights; Human Rights Education.

\section{RESUMEN}

\section{POLÍTICAS EDUCACIONALES, DERECHOS HUMANOS Y FORMACIÓN DE PROFESOR}

El artículo tiene como objetivo central presentar los resultados de una investigación realizada sobre la relación entre las políticas educativas, derechos humanos y formación docente. El texto se refiere a la Resolución 1 de 2012 del Consejo Pleno del Consejo Nacional de Educación -órgano ligado al Ministerio de Educación, que establece la inclusión de la legislación en derechos humanos en los currículos de los cursos de formación de profesores, centrados en los cursos de pedagogía. Fue realizado un relevamiento bibliográfico y legal con la perspectiva de mapear cómo las políticas educativas son contempladas en el proceso de formación de ese profesional. Desde el punto de vista teórico fueron tomados como referencia los siguientes autores: Novaes (2014) y Vieira (2007) con relación a las políticas educativas, Candau (1999) y Comparato (2008) en el estudio de los derechos humanos. Más allá de la Resolución 1 de 2012 del Consejo Nacional de Educación, fueron destacadas leyes y normas internacionales y nacionales que reglamentan las políticas de educación en derechos humanos. La investigación de carácter cualitativo, exploratorio y descriptivo, realizada entre 2016 y 2019 , tuvo como campo empírico tres universidades. Coordinador, profesores y estudiantes del curso de pedagogía fueron entrevistados y respondieron un 
cuestionario. Los resultados de la investigación indican que los contenidos y cuestiones sobre los derechos humanos aun requieren mayor visibilidad, inclusión en los currículos formales de los cursos de licenciatura, especialmente en los de pedagogía, en la práctica del aula, así como en actividades de investigación y extensión. Indican también que no siempre la transversalidad propuesta es atendida en los Proyectos Políticos Pedagógicos.

Palabras clave: Política educativa; Derechos Humanos; Educación en Derechos Humanos.

\section{INTRODUÇÃO}

0 texto introduz uma discussão sobre a evolução das políticas educacionais relacionadas à Educação em Direitos Humanos na formação do professor. Apresenta um levantamento das principais legislações internacionais e nacionais, analisando a evolução histórica da implantação das políticas no contexto educacional contemporâneo, e menciona uma pesquisa empírica realizada em Salvador

Além de larga revisão da literatura sobre o tema, durante a pesquisa empírica realizada em três universidades baianas, os pesquisadores entrevistaram coordenadores, professores e estudantes de três cursos de Pedagogia sobre as condições de inserção, no currículo, de questões relacionadas às políticas de direitos humanos e a formação dos futuros professores com relação às competências requeridas para trabalhar atendendo à legislação.

As políticas educacionais estão associadas às políticas de caráter mais amplo e resultam da ação "[...] do Estado no sentido de orientar, colocar em funcionamento e manter uma rede de ensino ou sistemas de educação" (NOVAES, 2014, p. 54) que mantenha atenção aos interesses da nação. Assim, é possível ponderar que as políticas educacionais são pensadas visando a atender demandas que surgem no contexto sociopolítico e educacional e são direcionadas a organizar os sistemas de ensino em suas diretrizes e finalidades, objetivando preparar o cidadão para o mundo do trabalho e a vida em sociedade.

De acordo com Vieira (2007), as políticas educacionais precisam expressar a multiplicidade e a diversidade das políticas sociais em um dado contexto histórico. 0 processo de elaboração das políticas educacionais e sua real aplicação "[...] não ocorre de maneira direta e linear, ou seja, a implementação de uma política educacional (programa ou projeto, etc.) não implica que se alcançarão resultados tais quais seus objetivos prenunciam" (NOVAES, 2014, p. 54).

Segundo Gatti e Barreto (2009, p. 53), "[...] mover-se em meio à legislação educacional sobre formação de professores, que comporta idas, voltas, remendos, complementos e iniciativas paralelas de poderes públicos, não é simples", exige um olhar atento e crítico com relação ao contexto e às finalidades das políticas.

Assim, nesta perspectiva crítica, é que o estudo apresenta a evolução das políticas voltadas para Educação em Direitos Humanos na formação do professor. 0 registro contempla legislações internacionais, nacionais, pactos, conferências, planos, pareceres e resoluções que foram criadas ao longo do contexto temporal delineado no estudo.

0 artigo foca a Resolução CNE/CP $\mathrm{n}^{\mathrm{o}}$ 1/2012 do Ministério de Educação - MECvia Conselho Pleno do Conselho Nacional de 
Educação - CPCNE -, publicada em 30 de maio de 2012, no Diário Oficial da União ${ }^{1}$, e assinada por Antônio Carlos Caruso Ronca, então presidente do Conselho Nacional de Educação - CNE. Essa Resolução estabelece as Diretrizes Nacionais para a Educação em Direitos Humanos, a serem consideradas pelas instituições de ensino básico e superior em todos os sistemas de ensino no território nacional. É composta por 13 artigos que legislam sobre a maneira e a forma como os sistemas de ensino devem implementar Educação em Direitos Humanos EDH - nos currículos em todos os níveis de ensino oficial.

Já são 07 anos desde sua publicação, e a obediência à norma estabelecida ainda está em fase de consolidação em grande parte dos currículos de cursos de formação de professores. A pesquisa indagou como vem ocorrendo o atendimento à Resolução $\mathrm{n}^{\circ}$ 1/2012 nos cursos de licenciatura em Pedagogia?

\section{EVOLUÇÃO DAS POLÍTICAS DE EDUCAÇÃO EM DIREITOS HUMANOS}

As políticas educacionais se relacionam com um conjunto de regras que norteiam as práticas nas instituições de ensino. São pensadas e criadas para atender ao contexto social, político e econômico de um país e, também, às demandas educacionais decorrentes desse contexto.

Como marco histórico e divisor de águas, a Declaração Universal dos Direitos Humanos - DUDH -, de 1948, consagra conquistas e direitos de todos os seres humanos, inclusive em educação. Desdobra-se no sentido primordial do "[...] reconhecimento da

1 Resolução CNE/CP 1/2012. Diário Oficial da União, Brasília, 31 de maio de 2012 - Seção 1 p. 48 igualdade essencial de todo ser humano em sua dignidade de pessoa, isto é, como fonte de todos os valores, independentemente das diferenças de raça, cor, sexo, língua, religião, opinião origem nacional ou social" (COMPARATO, 2008, p. 228).

Com a finalidade de assegurar os direitos consagrados na DUDH, a Organização das Nações Unidas (ONU), em 1966, reconheceu pactos internacionais relacionados aos direitos humanos: o Pacto Internacional sobre Direitos Civis e Políticos e o Pacto Internacional sobre Direitos Econômicos, Sociais e Culturais. Ambos foram ratificados e promulgados pelo Brasil, que assume a obrigação de cumpri-los mediante o Decreto n⿳⺈ 592, de 6 de julho de 1992.

A realização da I Conferência Internacional de Direitos Humanos, em Teerã, em 13 de maio em 1968, ocorrida vinte anos após a proclamação da DUDH, foi um evento que resultou em contribuições positivas e declara no Art. 17,

As aspirações da jovem geração de um mundo melhor, na qual sejam exercidos plenamente os direitos humanos e as liberdades fundamentais, devem ser incentivados ao máximo grau. É fundamental que os jovens participem na determinação do futuro da humanidade (PROCLAMAÇÃO DE TEERÃ, 1968, art. 17).

A Conferência de Teerã teve contribuições importantes para o desenvolvimento dos direitos humanos no contexto político e social, ainda que não se tenham efetivadas as políticas voltadas para educação em direitos humanos. A partir desta conferência, surgiram novos impulsos norteadores na busca da inserção de direitos humanos nas políticas educacionais.

A II Conferência Mundial de Direitos Humanos ocorreu em Viena, na Áustria de 14 a 25 de junho de 1993. Ela determina na 
Declaração e Programa de Ação de Viena (1993, art. 79) que "[...] todos os Estados e Instituições incluam os direitos humanos, o direito humanitário, a democracia e os Estado de Direito como matérias dos currículos de todas as instituições de ensino dos setores formal e informal.". Este foi um marco nos processos de divulgação e inclusão da educação em direitos humanos nas instituições de ensino formal e não formal, nas escolas, em todos os níveis do ensino.

As considerações, recomendações e ações estabelecidas no documento expressam, de forma clara, a política educacional da educação em direitos humanos e vai adiante recomendando aos Estados que "[...] desenvolvam programas e estratégias visando especificamente a ampliar o máximo a educação em direitos humanos e a divulgação de informações públicas nessa área, enfatizando particularmente os direitos humanos das mulheres" (DECLARAÇÃO E PROGRAMA DE AÇÃO DE VIENA, 1993, art. 81). Compreender esta trajetória é essencial, tendo em vista que o contexto histórico traz evidências que refletem como, onde e porque as políticas educacionais são pensadas e desenvolvidas, uma vez que a escolha das políticas envolve vários fatores que determinam os caminhos que a educação deve seguir para atingir seu propósito maior, que é formar sujeitos de direitos que tenham visão crítica e reflexiva, numa perspectiva de educação transformadora e inclusiva.

Em 1994, a ONU, através da Resolução n. - 49/184, aprovada em 23 de janeiro de 1994, proclama a Década das Nações Unidas para a Educação em matéria de Direitos Humanos, a ser realizada entre os anos de 1995 a 2005. A Resolução n.o 49/184 traz, em suas considerações inicias, que

[...] a educação em matéria de direitos humanos contribui para um conceito de de- senvolvimento compatível com a dignidade das mulheres e homens de todas as idades que tenha em conta os diversos segmentos da sociedade como crianças, os povos indígenas, as minorias e as pessoas deficientes. (ONU, 1994, p. 80).

O Plano de Ação para a Educação em Direitos Humanos para a década referida contempla duas partes. A primeira, o Plano de Ação Internacional da Década das Nações Unidas para a Educação em matéria de Direitos Humanos, (1995-2004). A segunda parte contém as Diretrizes para os Planos de Ação Nacionais para a Educação em matéria de Direitos Humanos.

Assim, EDH tornou-se um eixo fundamental no contexto mundial, sua efetiva inserção nos currículos dos sistemas educacionais é vista como um avanço para a educação de todos os países. Formar profissionais habilitados para esta missão é um dever de todos aqueles que se preocupam com um mundo melhor, sendo necessário criar espaços que possam difundir os valores e princípios da EDH.

As políticas educacionais voltadas para os direitos humanos ganham repercussão no Brasil em um contexto marcado por grandes transformações sociais, políticas e educacionais. Na esfera social, o momento ímpar foi a redemocratização do país, a partir de 1984, com as Diretas Já e, em 1985, a eleição, de forma indireta, do Presidente da República - o mineiro Tancredo Neves -, estabelecendo o fim do Governo Militar no Brasil. Posteriormente, a promulgação da Constituição Federal de 1988 - a Constituição Cidadã - traz, em seus fundamentos, a dignidade da pessoa humana (art.1 - III) e, em seus princípios, a prevalência dos direitos humanos (art.4 - III). Garante às comunidades indígenas educação em seu idioma materno, permite manifestações próprias 
das várias culturas que compõem o Brasil e possibilita aos "portadores de deficiência" participarem das escolas da "rede regular de ensino" (BRASIL, 1988, art. 208, inciso III). Em 1989, a Constituição do Estado da Bahia ratifica essas determinações.

Em 1996, a LDB - Lei de Diretrizes e Bases da Educação Nacional - n. 9.396/96, afirma, no art. 2ํ. " [...] a educação, dever da família e do Estado, inspirada nos princípios de liberdade e nos ideais de solidariedade humana" (BRASIL, 1996, art. 2º). Um dos princípios desta Lei é "[...] o respeito à liberdade e apreço à tolerância" (BRASIL, 1996, art. $3^{\circ}$ ), consagrando os valores que devem nortear e fundamentar o respeito aos direitos humanos e que devem ser inseridos nas instituições de educação. A seção $V$ desta Lei, intitulada $D a$ educação de adultos, traz dois artigos (37-38), voltados para a oferta de cursos, o acesso e a permanência dessa população no sistema de ensino. Na seção I - Das Disposições Gerais - o artigo 26, parágrafo 4 , determina que todas as etnias e culturas sejam contempladas nos estudos de história do Brasil.

Inspirado no Plano de Ação Internacional da Década das Nações Unidas para a Educação em Matéria de Direitos Humanos, o Brasil institui, em 1996, o Programa Nacional de Direitos Humanos - PNDH I -, que visava à redução das desigualdades e resguardar os direitos civis das pessoas. A III Conferência Mundial de Durban de combate ao Racismo, Discriminação Racial, Xenofobia e Intolerância, realizada em 31 de agosto a 08 de setembro de 2001, na África do Sul, estabeleceu o combate a toda forma de preconceito, um compromisso assinado por mais de 173 países que participaram da Conferência.

Em 2002, foi implantado o PNDH-II, que discutia “[...]a articulação dos cursos regula- res e dos cursos de extensão das universidades públicas e privadas, faculdades e outras instituições de ensino superior em torno de promoção e proteção dos direitos humanos" (PNDH, 2002, p. 31).

Nesta conjuntura, com a Portaria n. 998 de 2003, o Brasil cria o Comitê Nacional de Educação em Direitos Humanos - CNE$\mathrm{DH} / 2003$. Uma de suas finalidades era “[...] elaborar e aprovar o Plano Nacional de Educação em Direitos Humanos" (BRASIL, 2003, art.1ำ), e "monitorar o cumprimento das ações e medidas constantes no Plano Nacional de Educação em Direitos Humanos" (BRASIL, 2003, art. 1ํ). Desta forma, é consagrada a implantação de ações de ensino e pesquisa voltadas para a educação em direitos humanos nas modalidades de ensino, em todos os níveis da educação.

O Plano Nacional de Educação em Direitos Humanos (PNEDH) teve, em 2003, sua primeira versão. Ele foi construído com base em princípios que valorizam a igualdade, a justiça, a colaboração entre os países e a importância da educação em direitos humanos. Está centrado no fortalecimento da democracia, no respeito ao próximo, na dignidade da pessoa humana, na diversidade, na liberdade de expressão, na participação de forma igualitária e a preservação do meio ambiente sustentável. Repudia o preconceito em todas as suas formas e práticas. 0 sentido é que todos devem construir uma sociedade que promova o respeito às diferenças, à tolerância e à paz, pois somos os próprios atores da história, vivemos e construímos a nossa realidade uma vez que "[...] sem compromisso concreto não existe educação em direitos humanos" (CANDAU, 1999, p. 9).

$\mathrm{O}$ ano de 2003 foi rico em conquistas e implantação de políticas, através das lutas pelo reconhecimento, o clamor dos movimentos sociais negros e a conscientização 
da importância dos negros em nossa história. É imperioso expor que os legisladores brasileiros instituíram a Lei 10.639/03, que "[...] estabeleceu a obrigatoriedade da inclusão da História e Cultura Afro-Brasileira nos currículos oficiais das redes de ensino" (BRASIL, 2003), inserção esta que promove a valorização dos negros na nossa história e no desenvolvimento da cultura brasileira.

Em 2004, é publicada a Resolução CNE/ CP n. $\stackrel{0}{1}$, sobre as Diretrizes Curriculares Nacionais para a Educação das Relações Étnico-Raciais e para o Ensino de História e Cultura Afro-Brasileira e Africana, que regulamenta o cumprimento das diretrizes e que tem por objetivo, em seu Art. $2 \S 2$, “[...] o reconhecimento e valorização da identidade, história e cultura dos afro-brasileiros, bem como a garantia de reconhecimento e igualdade de valorização das raízes africanas da nação brasileira, ao lado das indígenas, europeias, asiática." (BRASIL, 2004, art. 2).

Depois da Década das Nações Unidas para a Educação em Direitos Humanos, a Organização das Nações Unidas - ONU institui em 2004, através da Resolução n. o 59/113aㅜ, o Programa Mundial de Educação em Direitos Humanos (PMEDH), com vigência de 2005-2019, dividido em três fases: a primeira, compreende ações voltadas para as escolas primárias e secundárias (2005/2007); a segunda, voltada à educação em nível superior, abraçando EDH para professores e educadores (2010/2015); e a terceira define a relevância de EDH para os profissionais de mídia e jornalistas (20152019).

0 PMEDH representa um marco singular no âmbito do desenvolvimento das políticas educacionais para a educação em direitos humanos em todo o mundo, apresentando os seguintes propósitos: a) Contribuir para o desenvolvimento de uma cultura de direitos humanos;

b) Promover o entendimento comum com base em instrumentos internacionais, princípios e metodologias básicas para a educação em direitos humanos;

c) Assegurar que a educação em direitos humanos receba a devida atenção nos planos nacional, regional e internacional;

d) Proporcionar um marco coletivo comum para a adoção de medidas a cargo de todos os agentes pertinentes;

e) Ampliar as oportunidades de cooperação e associação em todos os níveis;

f) Aproveitar e apoiar os programas de educação em direitos humanos existentes, ilustrar as práticas satisfatórias e dar incentivos para continuá-las ou ampliá -las e para criar novas práticas (UNESCO, 2005, p.11).

Esses propósitos visam a incentivar políticas educativas que promovam a EDH, por meio de atividades educativas que sejam de "natureza prática e devem estar encaminhadas ao estabelecimento de uma relação entre os direitos humanos e a experiência dos educandos na vida real." (UNESCO, 2005, p. 1).

No Brasil, em 2007, foi implantada a segunda versão do Plano Nacional de Educação em Direitos Humanos - PNEDH-II -, estruturado em eixos de atuação, focado na “Educação Básica; Educação Superior; Educação Não-Formal; Educação dos Profissionais dos Sistemas de Justiça e Segurança Pública e Educação e Mídia" (BRASIL, 2007, p. 11).

Em 2008, a Lei n. -11.645 , de 10 de março de 2008, que altera o artigo 26 da LDB, estabelece e torna obrigatório o estudo da história e cultura afro-brasileira e indígena, que deverá incluir "[...] diversos aspectos da 
história e da cultura que caracterizam a formação da população brasileira, a partir desses dois grupos étnicos [...]" (BRASIL, 2008, art. 26-A), reconhecendo a importância dos negros e índios na formação do povo brasileiro, bem como no desenvolvimento do país.

Dando continuidade aos programas nacionais voltados aos direitos humanos, foi aprovado o Programa Nacional de Direitos Humanos (PNDH-III), em 2009, que é estruturado em seis eixos orientadores e vinte cinco diretrizes. Os eixos são tais:

I) Interação Democrática entre Estado e Sociedade Civil;

II) Desenvolvimento e Direitos Humanos;

III) Universalizar Direitos em um Contexto de Desigualdades;

IV) Segurança Pública, Acesso à Justiça e Combate à Violência;

V) Educação e Cultura em Direitos Humanos;

VI) Direito à Memória e à Verdade (BRASIL, 2009, p. 227-229)

Todos os eixos são fundamentais para a implantação da EDH. Evidencia-se o eixo VEducação e Cultura em Direitos Humanos, que expressa, na Diretriz 19, três objetivos estratégicos, a seguir apresentados:

Diretriz 19: Fortalecimento dos princípios da democracia e dos Direitos Humanos nos sistemas de educação básica, nas instituições de ensino superior e nas instituições formadoras.

Objetivo Estratégico I: Inclusão da temática de Educação e Cultura em Direitos Humanos nas escolas de educação básica e em instituições formadoras.

Objetivo Estratégico II: Inclusão da temática da Educação em Direitos Humanos nos cursos das Instituições de Ensino Superior (IES).
Objetivo Estratégico III: Incentivo à transdisciplinaridade e transversalidade nas atividades acadêmicas em Direitos Humanos. (BRASIL, 2010, p. 191).

O Brasil consagrou, de forma definitiva, a relevância da inclusão da EDH nas instituições educacionais brasileiras, tanto de educação básica quanto de ensino superior, pois

deveria “[...] b) Promover a inserção da educação em direitos humanos nos processos de formação inicial e continuada de todos os profissionais da educação" (BRASIL, 2010, p. 191), e “[...] d) incluir conteúdos, recursos, metodologias e formas de avaliação da educação em direitos humanos nos sistemas de ensino da educação básica" (BRASIL, 2010, p. 192).

De acordo com o PMEDH, são características importantes no desenvolvimento da EDH no ensino superior:

A) desenvolvimento de políticas e de legislação para garantir a inclusão dos direitos humanos, em especial a educação em direitos humanos, no sistema de ensino superior:

(i) inclusão da educação em direitos humanos nas leis de educação ou adoção de legislação específica sobre educação em direitos humanos;

(ii) garantia de que toda a legislação esteja alinhada com os princípios da educação em direitos humanos e monitoramento de inconsistências dessa legislação (UNESCO, 2012, p.12).

Conforme o PMEDH, devem ser criadas e implantadas políticas educacionais e legislações que insiram a EDH nos sistemas de ensino superior, e que os princípios da EDH possam refletir nas práticas educativas desempenhadas pelos professores e por toda a gestão das instituições. A realização da Conferência Nacional de Educação (CONAE), de 28 de março a 1o de abril de 2010, foi um evento importante para a consolidação da EDH, 
[...] o Documento Final sinaliza para a importância de consolidação de uma concepção ampla de educação, que articule níveis, etapas e modalidades de ensino com os processos educativos ocorridos fora do ambiente escolar, nos diversos espaços, momentos e dinâmicas da prática social. (BRASIL, 2010, p.11).

0 referido documento chama atenção para o fato de que a EDH não acontece somente nos ambientes formais das escolas e universidades, sendo muito mais ampla e integral, e que tem por finalidade articular os vários sabres, culturas e vivências, com o objetivo de construir práticas educativas que reflitam a realidade dos educandos e educadores.

O Documento Final do CONAE/2010 apresenta seis eixos relativos à implantação das políticas públicas. Destacamos o “[...] o Eixo VI- justiça social, educação e trabalho: inclusão, diversidade e igualdade" (CONAE, 2010 , p. 123). Sabemos que cada tema apresenta peculiaridades específicas em diversos contextos; o importante é que, a partir desse eixo, são traçadas políticas públicas para a EDH, a serem introduzidas nos cursos de Pedagogia.

A CONAE indica em relação à Educação em Direitos Humanos:

c) Introduzir as temáticas de direitos humanos nos currículos da pedagogia e das licenciaturas, considerando o aspecto cognitivo e o desenvolvimento emocional e social dos/ das futuros/as profissionais vinculados ao processo ensino e aprendizagem, na perspectiva da proteção, promoção, bem como da reparação das violações dos direitos humanos (BRASIL, 2010, p. 162-163).

Essa reflexão leva a crer que, no decorrer do contexto da evolução das políticas voltadas para a EDH no Brasil, expostas até o momento, esta Conferência representou uma bússola orientadora, no que diz respei- to à importância dos direitos humanos nos cursos de formação e na preparação dos futuros profissionais que atuarão nas escolas e universidades.

Na sequência, em consonância com a CONAE, foi aprovada a Resolução CNE/CP n.o $1 / 2012$ de 30 de maio de 2012, que estabeleceu as Diretrizes Nacionais para a Educação em Direitos Humanos e que traz, ao longo de seus 12 (doze) artigos, os fundamentos, os princípios e a forma como deve ser inserida a EDH, na educação básica e no ensino superior, bem como direciona as diretrizes de inserção nos cursos que formam os profissionais de educação. No artigo $8^{\text {o }}$ da orientação para os cursos que formam os profissionais da educação, afirmando que EDH deve ser inserida como "[...] componente curricular obrigatório" (BRASIL, 2012, p. 2). Ou seja, em 2012, finalmente, foi editada uma norma específica, uma diretriz que insere a EDH na formação do professor como essencial no processo formativo.

Após a referida Resolução, houve um despertar para inúmeras diretrizes em prol de várias demandas educacionais existentes em nosso País. Neste contexto, incluem-se: a Resolução n. 3/2012 que estabelece diretrizes para o atendimento de educação escolar para populações itinerante; a Resolução n.ํ 02/2012, que normatiza as diretrizes curriculares para a educação ambiental; a Resolução n. ${ }^{\circ}$ 05/2012, que aborda as diretrizes curriculares nacionais para a educação escolar indígena; e a Resolução n. - 8/2012, que regulamenta as diretrizes curriculares nacionais para a educação escolar quilombola. Portanto, essas diretrizes relacionadas com o eixo central da educação em direitos humanos, devem ser efetivadas.

De suma relevância é o Plano Nacional de Educação - Lei 13.005/2014, de 25 de julho de 2014, que traz em suas diretrizes, no ar- 
tigo $2^{\text {o " }[. . .] ~ p r o m o c ̧ a ̃ o ~ d o s ~ p r i n c i ́ p i o s ~ d o ~ r e s-~}$ peito aos direitos humanos, a diversidade e a sustentabilidade" (BRASIL, 2014, art. 2º), em total alinhamento com os fundamentos e princípios consagrados pela EDH na Resolução CNE/CP n.ํ 01/2012. Tal junção das legislações tem o condão de fortalecer práticas educativas inclusivas e fundadas no respeito ao semelhante, ao diverso e ao meio ambiente em que vivemos.

A Política Nacional de Formação dos Profissionais da Educação Básica, criada pelo Decreto n. ${ }^{\circ}$ 8.752/16, em 09 de maio de 2016, trata da formação dos professores que atuarão na educação básica e terão a missão de difundir e promover educação em direitos humanos.

Nos objetivos da política citada, a formação dos profissionais da educação básica tem o dever de "[...] promover a formação de profissionais comprometidos com os valores de democracia, com a defesa dos direitos humanos, com a ética, com o respeito ao meio ambiente e com relações étnico-raciais baseadas no respeito mútuo [...]" (BRASIL, 2016, art. 3ํ) . Por tal objetivo, entende-se que a formação do professor deve ser fundamentada em múltiplos saberes, na perspectiva de desenvolver práticas educativas integradoras e colaborativas.

\section{EDH NA FORMAÇÃO DO PROFESSOR}

A EDH tem um sentido de mudança e transformação na forma de pensar e na maneira de agir. Cada formador de formador, o seja de professores, precisa assumir posicionamento crítico e proativo em relação aos acontecimentos sociais, políticos e educacionais. Tem o dever de desenvolver atitudes proativas em prol de uma cultura dos direitos humanos, acreditando sempre que paradigmas podem ser superados e que propostas educacionais inovadoras podem refletir, de maneira significativa, na formação do professor.

A EDH é uma temática recente no que diz respeito à sua inserção como um dos componentes obrigatórios nos cursos de formação inicial e continuada dos profissionais da educação, diretriz que passou a vigorar após a publicação da Resolução CNE/CP n.o $1 / 2012$.

Na perspectiva de reforçar a diretriz que trata da EDH como um dos componentes que devem orientar a formação do professor, tecemos, inicialmente, algumas considerações a respeito do que se entende por currículo, sua importância e relevância no contexto educacional da escola e das universidades.

De acordo com Coll (1996, p. 33-34), “[...] o currículo é um elo entre a declaração de princípios gerais e sua tradução operacional, entre a teoria educacional e a prática pedagógica, entre o planejamento e a ação, entre o que é prescrito e o que realmente acontece nas salas de aula". Percebemos na visão do autor, que o currículo pode ser considerado como uma bússola que orienta as ações e as práticas a serem inseridas e desenvolvidas no contexto educacional das instituições de ensino, orientando quais conteúdos devem ser ensinados, de que forma e com que finalidade, na perspectiva de atender a determinados objetivos. É tudo que se relaciona com o contexto educacional e com as ações a serem planejadas, executadas e avaliadas para o bom desempenho das atividades educacionais.

Dias e Porto (2010, p. 53) afirmam que “[...] o currículo norteado nos direitos humanos não pode ser considerado instrumento neutro, mas sim político, que se posiciona a favor dos diferentes e respeita a diversidade cultural", onde todos os conhecimentos e sa- 
beres devem ser valorizados, onde o diálogo possa ser o instrumento de mediação das ações e práticas educativas.

Tal assertiva nos leva à reflexão de que os conteúdos que serão ministrados sobre Educação em Direitos Humanos, nos cursos de formação de professores, têm uma importância salutar, mas devem estar imbricados de sentidos e inspirações simbólicas que sejam vivenciadas nas experiências reais do cotidiano desses futuros profissionais.

Desta forma, nada adiantará inserir a EDH no currículo das instituições de ensino e na formação do professor, se as ações práticas e experiências não forem atuantes e participativas em prol de um bem comum. É necessária uma atuação proativa e engajada no que se refere à educação em direitos humanos.

A EDH na formação de professor é uma temática nova no contexto formativo e, assim, enfrenta inúmeros obstáculos para sua efetivação na prática, ainda necessitando vencer inúmeros desafios, como apontam Candau e Sacavino (2013, p. 65-66), dentre eles:

1. Desconstruir a visão do senso comum sobre os direitos humanos, ainda está muito presente entre nós a representação de que a defesa dos direitos humanos está associada a "proteção de bandidos".

2. Assumir uma concepção de educação em direitos humanos e explicitar o que se pretende atingir em cada situação.

3. Articular ações de sensibilização e de formação.

4. Construir ambientes educativos que respeitem e promovam os direitos humanos. A educação em direitos humanos não pode ser reduzida à introdução de alguns conteúdos nos diferentes âmbitos educativos.

5. Incorporar a educação em direitos humanos no currículo escolar
6. Introduzir a educação em direitos humanos na formação inicial e continuada de educadores

7. Estimular a produção de materiais de apoio.

0 desafio 6, que se refere à introdução da temática da educação em direitos humanos na formação inicial e continuada dos professores, constitui um desafio a ser superado. A temática é recente e, relativamente, pouco divulgada e conhecida, apesar dos avanços significativos em termos da legislação educacional nas esferas nacional e internacional. Cresceu o número de artigos, livros e trabalhos, embora a inserção e as práticas educativas sejam muito pouco vivenciadas nos contextos das instituições e nas atividades práticas.

Para Rayo (2004, p. 192), “[...] os professores são uma peça-chave em um sistema democrático de educação, preocupado com os direitos humanos, com a paz e com a democracia", os professores têm papel central na educação em direitos humanos em todas as sociedades democráticas.

\section{A PESQUISA EMPÍRICA}

A investigação qualitativa ocorreu em Salvador, com o aval do Comitê de Ética da Universidade Católica do Salvador, emitido no Parecer n. $\stackrel{0}{ }$ 2.210.397, sob a orientação das Resoluções 466, de 2012, e 510, de 2016, do Conselho Nacional de Saúde - CNS - do Ministério de Saúde, que regulamenta a ética em pesquisas sociais.

A amostra composta por três coordenadores de três cursos de licenciatura em Pedagogia, de universidades distintas, 36 professores dos três cursos de licenciatura em Pedagogia investigados e 31 estudantes de licenciatura em Pedagogia das três universidades que constituíram o loci empírico da pesquisa realizada entre os anos de 2016 e 2019. 
Além das análises de documentos relativos ao projeto pedagógico dos cursos referidos e seus currículos, foram analisados materiais produzidos por alunos em final de curso de graduação em Pedagogia, especificamente aqueles considerados como Trabalho de Conclusão de Curso. Essas análises foram enriquecidas com os insumos dos instrumentos de coleta de dados que abrangeram: questionários impressos, entrevistas em profundidade com um roteiro, mas sem limitar-se ao roteiro predefinido e elaborado a partir das análises dos documentos e respaldados na literatura, além de observação de atividades, como reuniões de colegiado e aulas.

Das informações recebidas, das observações e das análises realizadas, é possível concluir que tem sido feito um esforço para atender a legislação sobre a formação de professores em EDH e a inserção de EDH em todos os currículos dos cursos e universidades investigadas. Cada uma das Universidades optou por ações distintas. Em uma, o trabalho com EDH é realizado de forma transversal, perpassando todas as disciplinas e atividades do curso; em outra, EDH é estudada como disciplina, mas de forma muito iniciante; no geral, a conclusão dos pesquisadores é que o tema é importante no seio de todas as três universidades, mas cada uma opta por formas distintas de ensinar os princípios que respaldam EDH. Todas tratam de temas como diversidade de gênero, etnia, religião e outros.

Essas discussões se estendem para além das aulas e dos muros das universidades. Fazem parte da vida cotidiana, familiar e social.

Além disso, em uma das universidades estudadas, há um grupo de pesquisa cadastrado no CNPq, que se dedica ao estudo do tema e engloba pesquisadores de graduação e pós-graduação.

\section{CONSIDERAÇÕES FINAIS}

A formação do professor é um processo contínuo, ou seja, é uma trajetória, um caminho a ser perseguido em busca do aperfeiçoamento constante, até porque há um aprendizado novo em cada instante da vida. E, como afirma Mészáros (2008, p.55), “[...] temos que reivindicar uma educação plena para toda a vida".

A preparação desse profissional num caráter humanístico deve envolver convivência social, familiar e laboral. 0 trabalho digno e o respeito aos diferentes é um direito humano. Na perspectiva da EDH, o educador tem a missão de promover práticas educativas que cultivem os princípios da igualdade, do respeito ao próximo e da tolerância, sendo que estas ações positivas provocam mudanças significativas na convivência entre os seres humanos e no meio social em que vivem.

Portanto, é necessário que as políticas, ações, os programas, planos e a Resolução n.ำ1/ 2012 sejam implementados e difundidos no contexto educacional das universidades, inseridos em seus projetos de desenvolvimento institucional, que sejam implantadas redes de colaboração em direitos humanos, para que possam compartilhar experiências, na perspectiva de reverter os desafios apontados que impedem a concretização da EDH nos cursos de formação do professor em muitas instituições de ensino.

Neste sentido, é imprescindível a inserção da EDH nos Projetos Pedagógicos dos Cursos - PPC - de formação de professores, a criação de espaços nas universidades onde a temática possa ser mais conhecida, discutida e debatida; que haja a sensibilização e articulação dos sujeitos que fazem parte do contexto das instituições educacionais em promover maior interação e participação das atividades com a finalidade de refletir 
sobre a EDH. Propostas assim podem ser uma das formas de se pensar a EDH no campo formativo.

É relevante que haja mais grupos de pesquisa sobre EDH cadastrados no CNPq para que sejam realizados mais estudos aplicados ao contexto do nordeste do Brasil, região com muitos disparates com relação a não observação dos direitos humanos, sobretudo das populações com menos escolaridade.

Mais pesquisas são requeridas sobre o tema e mais atividade prática de aplicação das políticas e da legislação. É relevante monitoramento e acompanhamento das políticas educacionais brasileiras e internacionais as quais que nem sempre são postas em prática no Brasil. Como exemplo de desrespeito à legislação vigente no país, é possível citar a redução da oferta dos cursos de ensino fundamental e médio dirigidos a potenciais estudantes jovens e adultos, de 15 anos ou mais, num país cujas estatísticas mostram um contingente de 11, 8 milhões de analfabetos nessa corte. Este é um desrespeito ao direito à educação ao longo da vida.

\section{REFERÊNCIAS}

BRASIL. Decreto no 592, de 6 de julho de 1992. Atos Internacionais. Pacto Internacional sobre Direitos Civis e Políticos. Promulgação. Disponível em: http://www.planalto.gov.br/ccivil_03/decreto/1990-1994/d0592.htm. Acesso em: 28 jun. 2019

. Lei n. ${ }^{0}$ 9394, de 20 de dezembro de 1996. Estabelece as Diretrizes e Bases da Educação Nacional. Disponível em: http://www.planalto. gov.br/ccivil_03/leis/L9394.htm. Acesso em: 05 abril. 2015.

Ministério da Educação. Conselho Nacional de Educação. Parecer n. - CNE/CP 009/2001, de 8 de maio de 2001. Diretrizes Curriculares Nacionais para a formação de professores da Educação Básica, em Nível Superior, Curso de Licenciatura, de Graduação Plena. Brasília, Disponível em: http://portal.mec.gov.br/ cne/arquivos/pdf/009.pdf. Acesso em: 10 out. 2015.

Secretaria de Direitos Humanos da Presidência. Programa Nacional de Direitos Humanos (PNDH - II). Brasília, 2002. Disponível em: http://www.dhnet.org.br/dados/pp/edh/ pndh_2_integral.pdf. Acesso em: 25 abril 2015

. Decreto n.o 4.229, de 13 de maio de 2002. Dispõe sobre o Programa Nacional de Direitos Humanos - PNDH, Instituído pelo Decreto n.- 1.904, de 13 de Maio de 1996, e dá outras providências. Brasília, Disponível em: https:// www2.camara.leg.br/legin/fed/decret/2002/ decreto-4229-13-maio-2002-452043-publicacaooriginal-1-pe.html. Acesso em: 15 jan. 2015.

Secretaria Especial dos Direitos Humanos. Portaria n. -98 , de 9 de julho de 2003. Institui o Comitê Nacional de Educação em Direitos Humanos. Disponível em: http://www. sdh.gov.br/assuntos/conferenciasdh/12a-conferencia-nacional-de-direitos-humanos/educacao-em-direitos-humanos/portaria-no-98-de9-de-julho-de-2003. Acesso em: 10 out. 2016.

Comitê Nacional de Educação em Direitos Humanos. Plano Nacional de Educação em Direitos Humanos. Brasília: Secretaria Especial dos Direitos Humanos, Ministério da Educação, Ministério da Justiça, UNESCO, 2007, 76 p. Disponível em: http://portal.mec.gov.br/index. php?option=com_docman\&view=download\&alias=2191-plano-nacional-pdf\&category_slug=dezembro-2009-pdf\&Itemid=30192 . Acesso em 15 de jan. 2015

Lei n. ${ }^{\circ}$ 11.645, de 10 de março de 2008. Altera a Lei no 9.394, de 20 de dezembro de 1996, modificada pela Lei no 10.639, de 9 de janeiro de 2003, que estabelece as diretrizes e bases da educação nacional, para incluir no currículo oficial da rede de ensino a obrigatoriedade da temática "história e cultura afro-brasileira e indígena". Brasília. Disponível em: http://www.planalto.gov.br/ccivil_03/_ ato2007-2010/2008/lei/111645.htm. Acesso em: 10 jul. 2016

Decreto n. $\stackrel{6755}{ }$, de 29 de janeiro de 2009. Institui a Política Nacional de Formação de Profissionais do Magistério da Educação Básica, disciplina a atuação da coordenação de aperfeiçoamento de pessoal de nível superior - Capes no fomento a programas 
de formação inicial e continuada, e dá outras providências. Brasília, Disponível em: https:// www.capes.gov.br/images/stories/download/ legislacao/Decreto-6755-2009.pdf. Acesso em: 15 out. 2015.

Secretaria de Direitos Humanos da Presidência. Programa Nacional de Direitos Humanos (PNDH-3). Brasília: SEDH/PR, 2010. 308 p. Disponível em: <http://www.sdh.gov.br/ assuntos/direito-para-todos/programas/pdfs/ programa-nacional-de-direitos-humanos-pndh-3> Acesso em: 10 maio.2015

Ministério da Educação. Conselho Nacional de Educação. Parecer CNE/CP n.o 8/2012. Diretrizes Nacionais para a educação em Direitos humanos. Diário Oficial da União, Brasília, DF, 30 maio 2012, Seção 1, p. 33. Disponível em: http://www.sdh.gov.br/assuntos/direito-paratodos/pdf/ParecerhomologadoDiretrizesNacionaisEDH.pdf. Acesso em: 10 ago. 2016.

Resolução n. ㄱ, de 16 de maio de 2012. Define Diretrizes para o atendimento de Educação Escolar para populações em situação de itinerância. Brasília, Disponível em: http://etnicoracial.mec.gov.br/images/pdf/ rceb003_12_educacao_itinerncia.pdf. Acesso em: 10 set. 2016

. Resolução n. ${ }^{\circ}$ 1, de 30 de maio de 2012. Estabelece Diretrizes Nacionais para a Educação em Direitos Humanos. Disponível em: http://portal.mec.gov.br/index.php?option=com_docman\&view=download\&alias $=10889-\mathrm{r}-$ cp001-12\&category_slug=maio-2012-pdf\&Itemid=30192. Acesso em: 10 jan. 2015.

Resolução n.o 2, de 15 de junho de 2012. Estabelece as Diretrizes Curriculares Nacionais para a Educação Ambiental. Brasília. Disponível em: http://portal.mec.gov.br/index. php?option $=$ com_do $\mathrm{cman} \&$ view $=$ downloa d\&alias=10988-rcp002-12-pdf\&category_slu$\mathrm{g}=$ maio-2012-pdf\&Itemid=30192. Acesso em: 10 agosto. 2016.

. Resolução n.o 5, de 22 de junho de 2012. Define Diretrizes Curriculares Nacionais para a Educação Escolar Indígena na Educação Básica. Brasília. Disponível em: http://portal.mec. gov.br/index.php?option=com_docman \&view=download\&alias=11074-rceb005-12-pdf\&category_slug=junho-2012-pdf\&Itemid=30192>Acesso em: 05 jul. 2016
Resolução n.o 8, de 20 de novembro de 2012. Define Diretrizes Curriculares Nacionais para a Educação Escolar Quilombola na Educação Básica. Brasília, Disponível em: http://portal.mec.gov.br/index.php?option $=$ com_docman\&view=download \&alias =11963-rceb008-12-pdf\&category_slug=novembro-2012-pdf\&Itemid=30192 $>$ Acesso em:12 abril 2016.

Ministério da Educação. Secretaria de Educação Básica. Secretaria de Educação Continuada, Alfabetização, Diversidade e Inclusão. Secretaria de Educação Profissional e Tecnológica. Diretrizes Curriculares Nacionais para a Educação Básica: diversidade e inclusão. Brasília: Conselho Nacional de Educação, 2013. $480 \mathrm{p}$

Lei n. 9 13.005, de 25 de junho de 2014 . Aprova o Plano Nacional de Educação - PNE e dá outras providências. Brasília, Disponível em: http://www.planalto.gov.br/ccivil_03/_ ato2011-2014/2014/lei/l13005.htm. Acesso em: 10 out. 2015 .

Constituição da República Federativa do Brasil. São Paulo: Saraiva 2014.

Decreto n. -9.752 , de 9 de maio de 2016. Dispõe sobre a Política Nacional de Formação dos Profissionais da Educação Básica. Brasília, Disponível em: http://www.planalto. gov.br/ccivil_03/_Ato2015-2018/2016/Decreto/D8752.htm. Acesso em: 10 dez. 2016.

CANDAU, Vera Maria. OFICINAS APRENDENDO E ENSINANDO. Educação em Direitos Humanos: uma proposta de trabalho. Rede Nacional de Direitos Humanos, Novameria/PUC-Rio, p.112, 1999. Disponível em: http://www.dhnet. org.br/direitos/militantes/veracandau/candau_edh_proposta_trabalho.pdf Acesso em:12 jan. 2016

CANDAU, Vera Maria; SACAVINO, Susana Beatriz. Educação em direitos Humanos e formação de professores. Educação, Porto Alegre, v. 36, n. 1, p.59-66, jan./abr. 2013.

COLL, César. Psicologia e Currículo: uma aproximação psicopedagógica à elaboração do currículo escolar. São Paulo: Ática, 1996

COMPARATO, Fábio Konder. A afirmação histórica dos direitos humanos. $6^{a}$ ed., São Paulo: Saraiva, 2008. 
[CONAE] CONFERÊNCIA NACIONAL DE EDUCAÇÃo, de 28 de março a $1^{\circ}$ de abril de 2010. Disponível em: http://conae.mec.gov.br/images/stories/pdf/pdf/documetos/documento_ final_sl.pdf. Acesso em 10 de fevereiro 2016.

DECLARAÇÃO E PROGRAMA DE AÇÃO DE VIENA. 1993. Disponível em: http://www.pge. sp.gov.br/centrodeestudos/bibliotecavirtual/ instrumentos/viena.htm. Acesso em: jul./ago. 2015

DECLARAÇÃO UNIVERSAL DOS DIREITOS HUMANOS. Adotada e Proclamada Pela Resolução n. 217 A (III) da Assembléia Geral das Nações Unidas em 0 de Dezembro de 1948. Brasília, Disponível em: http://unesdoc.unesco.org/images/0013/001394/139423por.pdf. Acesso em: 10 dez. 2015.

DECLARAÇÃo e Programa de Ação adotados na III Conferência Mundial de Combate ao Racismo, Discriminação Racial, Discriminação Racial, Xenofobia e Intolerância Correlata de 31 de agosto a 8 de setembro de 2001. Durban, África do Sul. Disponível em: https:// goo.gl/cidFPu. Acesso em: 15 mar 2016.

DIAS, Adelaide Alves; PORTO, Rita de Cassia Cavalcanti. A PEDAGOGIA E A EDUCAÇÃO EM DIREITOS HUMANOS: subsídios para a inserção da temática da Educação Direitos Humanos nos cursos de Pedagogia. In: FERREIRA, Lúcia de Fátima Guerra; ZENAIDE, Maria de Nazaré Tavares; DIAS, Adelaide Alves. DIREITOS HUMANOS NA EDUCAÇÃO SUPERIOR: subsídios para a Educação em Direitos Humanos na Pedagogia. João Pessoa: Universitária, 2010. p. 29-68

GATTI, Bernadete Angelina; BARRETO, Elba Siqueira de Sá (Org.). Professores do Brasil: impasses e desafios. Brasília: Unesco, 2009. 294 p.

MÉSZÁROS, István. A educação para além do capital. Tradução Isa Tavares. $2^{\mathrm{a}}$ ed. São Paulo: Boitempo, 2008. 124 p.

NOVAES, Ivan Luiz. Construção do Projeto de pesquisa sobre políticas e Gestão da Educação. Salvador: EDUNEB, 2014

ORGANIZAÇÃO DAS NAÇÕES UNIDAS. Educação em matéria de Direitos Humanos e Tratados de Direitos Humanos da Série Década das Nações Unidas para a Educação em matéria de Direitos Humanos 1995 -2004. Genebra, 1999.

PACTO INTERNACIONAL SOBRE DIREITOS ECONÔMICOS, SOCIAIS E CULTURAIS. 1992. Disponível em: https://www.oas.org/dil/ port/1966\%20Pacto $\% 20$ Internacional $\% 20$ sobre\%20os\%20Direitos\%20Econ\%C3\%B3 micos, $\% 20$ Sociais $\% 20$ e $\% 20$ Culturais.pdf Acesso em: jan/fev, 2015

PROCLAMAÇÃO DE TEERÃ. Proclamada pela Conferência de Direitos humanos em Teerã a 13 de maio de 1968. Disponível em: http:// www.dhnet.org.br/direitos/sip/onu/doc/teera.htm . Acesso em: 10 de julho 2016

RAYO, José Tuvilla. Educação em direitos humanos: rumo a uma perspectiva global. Trad. Jussara Haubert Rodrigues. Porto Alegre: Artmed, 2004, 247p.

UNESCO. Programa Mundial para Educação em Direitos Humanos. Brasília, 2005. Disponível em: http://unesdoc.unesco.org/images/0014/001478/147853por.pdf. Acesso em: 12 de abril de 2015.

UNESCO. Plano de Ação: Programa Mundial para Educação em Direitos Humanos. Segunda fase. Brasília: UNESCO, 2012. Disponível em: https://unesdoc.unesco.org/ark:/48223/ pf0000217350_por . Acesso em: 15 jul. 2016.

VIEIRA, Sofia Lerche. Política (s) e Gestão da Educação Básica: Revisitando conceitos simples. RBPAE, v.23, no 1, p. 53-69, jan./abr. 2007.

Recebido em: 19/02/2019

Aprovado em: 07/05/2019 